\title{
PRAGMIATIZACIÓN DEL COGITO, ÉTICA Y FEMINISMO EN FRANÇOIS POULLAIN DE LA BARRE
}

Celia Amorós

\section{La critica al prejuicio y la universalidad de "le bon sens"}

En el ámbito de lo que ha llamado Henry Piéron "la influencia social de los principios cartesianos" cobra toda su pertinencia lo que querriamos que fuera un homenaje a la obra de un filósofo, discipulo de Descartes, injustamente olvidado en la historiografia convencional de la Filosofia, cuyo nombre fue François Poullain de la Barre. Nuestro cartesiano sui generis —pues su personalidad filosólica no es exactamente la de un epigono- publicó en 1673 una obra titulada De l'Égalité des deux sexes. Discours physique et moral ou l'on voit l'imporlance de se defaire des prejuges. El titulo es ya suficientemente expresivo: se trata de derivar, en favor de los derechos de las mujeres, las implicaciones de la critica cartesiana al prejuicio, la tradición y el argumento de autoridad, así como del dualisno mente-cuerpo.

En De l'Égalité des detur sexes, el planteamiento de Poullain es cartesianamente nítido y podría resumirse asi: el prejuicio relacionado con la desigualdad de los sexos es el más obstinado y ancestral, ergo si podemos refutarlo (derivando de las premisas cartesianas que "l'esprit" no tiene sexo), a fortiori lo podremos hacer con todos los demás; o, dicho de otro modo, habremos contrastado las condiciones de posibilidad, no sólo lógicas sino prigmáticas del programa cartesiano de lucha contra el prejuicio ampliado - con connotaciones ilustradas-al ámbito de la praxis social.

\section{Pragmatización del cogito e inflexión ético-politica del cartesianismo}

De este modo, en la medida en que "le bon sens" se contrapone radicalmente como instancia critica al saber tradicional instituido, $y$, dado que son sobre todo mujeres las que tradicionalmente han sido excluidas de ese saber - sometido ahora a la crítica racional por su carencia de método y de fundamentación en la unidad de la razón-, resultan ser ellas las menos corrompidas. Su propia marginación les ha ahorrado el farragoso bagaje de estratos de saber acriticamente asumidos. Estản así mejor preparadas que nadie para ejercer "le bon sens" con toda soltura y menos hipotecas. Viajeras sin equipaje por el nuevo continente de "le bon sens" no sólo lo tienen en sentido eminente: son sus portadoras por antonomasia.

En Descartes, el cogito se planteaba en el nivel de inmanencia del propio pensamiento y de la res cogitans que - problemáticamente, como se ha senalado- se infiere del nismo. En el ámbito de las condiciones del propio pensamiento, el cogito puede ser interpretado como lo que elimina la plausibilidad de la hipótesis del genio maligno: la existencia del Deus deceptor es descartada porque la posibilidad misma de que yo me piense como conciencia engaitada al establecer mi propia conciencia como existente implica la imposibilidad de que me esté engañando al pensarme a mi misma como supuesta conciencia engoñada; esta imposibilidad, que determina la centeza de la existencia de mi pensamiento, es lo que confiere en última instancia a la duda su privilegio epistemológico. Ahora bien, este privilegio no puede transeender el ámbito mismo de la conciencia, en cuanto que se refiere exclusivamente a las condiciones de posibilidad de la misma. Mi existencia en tanto que conciencia unida a un cuerpo $y$, en esa misma medida, sujeto de acciones que transcienden la operación de autorreflexión slel propio pensamiento no podria ser en Descartes objeto de certeza apodictica sino meramente moral, es 
decir, suficiente a los efectos de "los usos de la vida y de las conversaciones ordinarias", tal como le escribió a la Princesa Isabel del Palatinado (Carta del 28-V1-1643). En efecto, cn la parte 4 de los Principia distingue "dos clases de certeza. La primera es llamada moral, es decir, sifficiente para regular nuestras costumbres, o del mismo orden que el de las cosas con respecto de las cuales no acostumbramos en absoluto a dudar concernientes al comportamiento en la vida, aunque separnos que puede ocurrir, hablando en términos absolutos, que sean absolutamente falsas". La duda, al no catapultarnos a la certeza desde el momento en que entra en juego la unión del alma y el cuerpo - "hay dos cosas en el alma humana, una de las cuales es que piensa, la otra que, al estar unida al cuerpo, puede actuar y padecer con èl" (2l mayo 16+3)-, sería inhibidora de toda acción. Por esa razón Descartes, en el terreno de la moral, sustituye la certeza de carácter fundamentalista por lo que seria su correlato pragmático: la resolución y la firmeza en la voluntad.

Sin embargo, por otra parte, la propia duda es una acción de la voluntad libre. Así interpreta Sartre "La duda cartesiana como expresión máxima de la soberania de la libertad". La puesta entre paréntesis de toda certeza que la hipótesis del genio maligno conlleva pende en realidad de una certeza: la de mi propia actividad de suspension, como acto de mi conciencia critica que puede ponerlo todo en suspenso excepto la suspensión misma que lo mantiene en suspenso (estoy dudando, ergo mi duda está siendo en tanto que opera). Poullain, en este stntido, no hará sino radicalizar la concepción de la duda como acción. Nuestro autor estima por otra parte - gran heterodoxia cartesiana-, que "es más fácil asegurarnos de que una cosa es que saber aquéllo que es"; así, "las primeras dudas que nos podemos formar y las más fáciles de disipar son las que se refieren a la existencia de las cosas". "Si de algo debemos asegurarnos en primer lugar, es de la existencia de nosotros mismos. $Y$ la duda que podriamos tener acerca de ello lleva consigo su aclaración, puesto que, al ser una acción verdadera, que no puede pertenecer a la Nada, parece que un espíritu atento no podria dudar seriamente acerca de si existe". Asi pues "concluyo...que yo existo, yo que pienso, porque actio; al haber una cosa de la que no puedo separarme que me da placer y dolor, sin que yo contribuya a ello, e incluso muy a menudo a mi pesar, es necesario que esta cosa, que yo llano mi cuerpo, exista realmente". Como lo señala Piéron, estamos aqui bien lejos de Descartes. Pues afirma Poullain: "Asi como concluimos que tenemos un cuerpo, porque lo sentimos, concluimos que hay otros alrededor de éste, porque los sentimos y nos impactan por las impresiones que producen sobre nosotros". Ciertamente, Poullain no capta aqui adecuadamente cuàles son los requisitos cartesianos del conocimiento claro y distimso. Pero la razón de ello no es tanto una incapacidad o insensibilidad teórica como una diferencia de intereses con repecto a Descartes; $y$, justamente por ello, su pragmatización del cogito va a hacer posible que las cuestiones éticas, politicas y sociales se adectien a las exigencias criticas del método cartesiano. Como lo ha puesto de manifiesto Michèle Le Doeuff, la posibilidad de la fundamentación de una ética racional queda bloqueada, que no meramente pospuesta - como parece sugerir la inexacta versión de "moral provisional"-, en el cartesianismo. Y la razón de ello es que en Descartes encontramos, si lo comparamos con las antiguas teorios de la sabiduria, una inversión en lo que concierne a la relación entre lo ético y lo teórico. Para las antiguas teorias de la sabiduria "hay que tratar de conocer porque la vida buena depende del saber. Pero si la ética dependiera de lo teórico, si la ética fuera la finalidad de la empresa especulativa, entonces lo teórico estaria ordenado a lo ético. Descartes no sólo separa la práctica de la teoria, excluy'e la moral de la empresa metódica, sino que invierte el esquema de la sabiduria antigua: si se da una moral con el empeño de continuar instruyéndose, entonces lo ético está ordenado a lo reórico; se da una 
regla de vida que haga posible la empresa especulativa". A su vez, esta inversión está intimamente relacionada, para Le Doeuff, con el problema del estatuto epistemológico de la union sustancial, pues ¿cómo podria la práctica de la filosofia regular la conducta si el cuerpo no está sustancialmente unido al alma? Poullain, al poner el śnfasis en la acción como producto de la mente en cuanto unida al cuerpo, $y$ al promocionar mestra propia apercepción como sujetos actuantes a la certeza del cogito - la duda, en definitiva, es una acción-, le da una inflexión al cartesianismo por la cual éste se configura como una ética y como un programa de critica politica y social. La orientación de nuestras acciones puede asi ser sometida al criterio de las ideas claras y distintas, al menos lo suficientemente claras y distintas - cartesianismo un tanto heterodoxo, pero dotado de unas virtualidades insólitas con respecto a su ámbito originalcomo para combatir con eficacia el oscurantismo del prejuicio. La regla de evidencia se conviente asi en criterio de irracionalización -es lo que le interesa a Poullain, como interés de la razón- de todo poder no legítimo y de toda violencia, que serán de ese modo interpelados en tanto que no se fundan en la razón ni pueden ser contrastados con "le bon sens". De este modo, podriamos decir que Poullain repone el esquema de la sabiduria antigua, a diferencia del planteamiento de Descartes, aunque lo hace en una clave diferente: el saber estará de nuevo en función de la vida buena, si bien la vida buena es entendida ahora como la emancipación de la razón del reino del prejuicio. Pues "no hay nadie que no busque el ser feliz, y es a ello a lo que tienden todas nuestras acciones; $y$ uno sólo puede serlo con solidez por las ideas claras y distintas..." De acuerdo con Le Doeuff, en Descartes no se teoriza el valor del conocimiento como fuente de felicidad: se confiesa. En Poullain, como podemos ver, de nuevo se teoriza. Nuestro autor propone la asunción de la filosofia cartesiana en tanto que es la que mejor se adeciia a sus principios - además de ser una lilosofia francesa, que ahorra los esfuerzos de aprender las lenguas clásicas, indispensables para entender correctamente a los autores antiguos-. Se inscribe así, como el hombre de su tiempo que era, en la "querelle des anciennes et des modernes": publicó en 1672 "Rapports de la langue francaise, pour traduir èléganment". Sus esfuerzos convergen con los de Las Preciosas en el establecimiento y la consolidación de la lengua francesa como lengua viva versus las lenguas muertas, en la linea de la polémica que prestigiaba el libro renacentista como libro vivo, en tanto que producto de una lectura directa de la naturaleza, versiss el libro muerto que cra generado por la mera erudición medieval. Si recomienda a Descartes es por ser éste "uno de los filósofos más razonables que tenemos, cuyo método es el más tuiversal, el más natural y $\mathrm{el} \mathrm{más} \mathrm{conforme} \mathrm{al} \mathrm{buen} \mathrm{sentido} \mathrm{y} \mathrm{a} \mathrm{la} \mathrm{naturale-}$ $z a$ del espíritu humano, asi como el más adecuado para discernir lo verdadero de lo falso..." Como lo señala Pićron, alirma el espiritu critico, con una fidelidad cartesiana, contra el propio Descartes. Piéron lo considera sin embargo una mente "de envergadura menor" que no comprende el alcance metafisico que para Descartes tiene la duda: sólo alcanza a ver el valor práctico de la misma. Por nuestra parte, sólo alcanzamos a ver en esta apreciación de Piéron una idea convencional más que discutible acerca de lo que significa ser filósolo: Poullain, hijo de Descartes y del movimiento preciosista, representa un momento particularmente lúcido y pregnante de la autoconciencia critica de la especie en una fase muy significaliva de su evolución social y cultural. Nadie duda que Descartes constituy'e el punto de engarce potente, en el que la critica a la compartimentalización del saber renacentista (Turró) y la critica a la estratificaciör estamental de la sociedad se anudan y encuentran un catalizador en la idea de "público". El "pủblico" es identificado por Habermas como el nuevo sujeto emergente del razonamiento generalizador que la burguesia reivindica para la funcionalidad del tráfico de mercancias - versus el ajuste caso por caso propio de la lógica de l'dncien Rigime-; a la vez. el "püblico" es 
el interlocutor al que se puede dirigir el teórico del método de la nueva ciencia, pues le es coextensivo el bon sens como el correlato de la intersubjetividad que este nuevo proceder melódico requiere. "Quiero que me entiendan hasta las mujeres", dirá Descartes. Asi, este método, en tanto que apela como a su condición de posibilidad en última instancia a la unidad de la razón —que remite a su vez a la unidad de la especie-identificará el verdadero saber, el que se aticne al orden que viene determinado por la estructura misma de la subjetividad humana, con el saber unitario. Ahora bien: si el método verdadero en cuanto uno ha podido unificar los objetos de las ciencias de la naturaleza —el álgebra y la geometria en la mathesis universalis, para acabar subsumiendo en su proceder la óptica y la fisiologia-, no se ve por qué no habria de hacerlo con los ámbitos de lo que llamamos hoy ciencias sociales: el origen de la sociedad, del Estado. Aqui radica la genialidad de Poullain, fundador de las ciencias sociales - como to ha senalado Cliristine Faure, mucho antes que Comte-, en el mismo movimiento de radicalización de las virtualidades universalizadoras del cartesianismo que le llevó a postular la igualdad entre los sexos. Asi, la portadora del bon sens que es la mujer se veria conducida a indagar qué es lo que ha llevado a los hombres a constituir una sociedad civil. "Los consideraria, pues, como fuera de esta sociedad y encontraria que todos ellos eran libres e iguales, y con la autoconservación como su única inclinación y un derecho igual sobre todo to que les fuera necesario. Pero observaria que, como esta igualdad llevaria a una guerra o a una desconfianza continuas, lo cual sería contrario a su fin, la luz natural dictaria que ellos no podrian vivir en paz sin reducir cada cual su derecho y sin hacer convenciones ni contratos, asi como que, para convertir en válidas dichas acciones y librarse de inquietud, seria necesario tener recurso a un tercero, el cual, al tomar la autoridad, obligaria a cada cual a cumplir lo que habia prometido a los otros; que, al no haber sido elegido este último sino para ventaja de sus sujetos, no deberia en absoluto tener otra finalidad, y que, para llegar al fin de su institucionalización, sería preciso que fuera amo de los bienes y de las personas, de la pazy de la guerra". Desde la pragmatización del cogito llegamos, pues, mediante la reconstrucción de l'ordre des raisons, a una suerte de génesis del Leviatán avant le lettre con impregnaciones rousscaunianas.

\section{Una bisagra entre Descartes y Rousseau}

Es curioso encontrar en una de las obras de Poullain de la Barre - publicada en 1675, titulada Traite de l'Excellence des hommes y escrita con una buena dosis de ironia- una critica a la valoración positivista del progreso cientifico y técnico, junto con una proyección en el estado "le naturaleza originario de la idea cartesiana del "bon sens", como "le plus répandu" antes de la decadencia y la corrupción que conllevaron las instituciones asi como un desarrollo técnico no racional, en tanto que no regulado por este "bon sens" cartesiano vencido del lado de la rizón práctica avant la lettre. Se podria hablar así de una bisagra, tan curiosa como lógica desule el punto de vista de una reconstrucción estructural de las posibilidades combinatorias susceptibles de ser explotadas a partir de la matriz del complejo ideológico de la llustración, entre Descirtes y Rousscau. Esta bisagra, como el eslabón débil y precario en los procesos evolutivos, en la medida en que se sitúa en las encrucijadas mismas a partir de las cuales se bifurcan las lineas que llegan a estabilizarse, es precisamente la que se pierde y "se olvida".

¿Leyó Rousseau las obras de Poullain de la Barre? Es la pregunta obvia que surge ante la pregnancia de estos textos, y que intérpretes como Henry Grappin, Madeleine Alcover, Christine Fauré, entre otros, se han planteado. Existe, sin duda, la posibilidad cronológica, la plausibilidad local - Poullain vivió, desde que abandonó el sacerdocio católico por el calvinismo en 1688, retirado en Ginebra-y diversos indicios en cuya interpretación y discusión no pode- 
mos entrar aquí. Nos limitaremos a indicar que párrafos muy significativos de Rousseau en "La educación de Sofia", vgr: "esta desigualdad (entre los sexos) no es obra del prejuicio sino de la razón" cobran una nueva dimensión de inteligibilidad si se releen a contraluz de su referente polémico silenciado u olvidado. Poullain había dicho: "la desigualdad entre los sexos no es obra de la razón sino del prejuicio". Rousseau se refiere asimismo polémicamente a "la manera de argumentar propia de los galantes partidarios del bello sexo", trivializando así la obra de Poullain, quien explotó asimismo la antropología cartesiana para fundamentar la igualdad: "l'esprit n'a pas de sexe". 